Vol.15, No. 56, July, 2020, 753-762

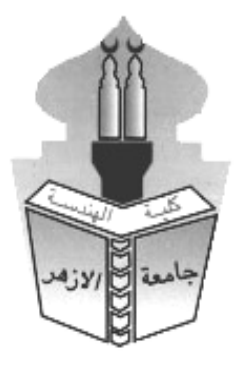

\title{
EXPERIMENTAL STUDY ON CONCRETE REINFORCED With HUMAN AND HORSE HAIR FIBERS
}

\author{
Zakaria Hameed Awadallah Ibrahim \\ Civil Engineering Department, Faculty of Engineering, Al-Azher University, Qena, Egypt \\ E-mail: Zakariahameed@azhar.edu.eg
}

\begin{abstract}
Concrete is good in compression but week in tension that is, concrete is a brittle material. So, in order to improve the tensile properties of concrete, short fibers are used. Human and horse hairs consider a bio material and have a good strong in tension; hence it can be used as a fiber reinforcement material. Hair Fiber (HF) an alternate non-degradable matter is available in abundance and at a very cheap cost. It also creates environmental problem for its decompositions. The aim of this research work is to find out the properties (mechanical) of hair fiber reinforced concrete. Experiments were conducted on concrete cylinders, cubes and prisms with various percentages of human and horse hairs fibers i.e. $0 \%, 1 \%, 1.5 \%$, and $2.5 \%$ by weight of cement. Two grades of reference plain concrete were used, 20 and $40 \mathrm{MP}_{\mathrm{a}}$. The results showed that there is an increment in the various mechanical properties and strength of concrete by addition of human and horse hairs to concrete.
\end{abstract}

\section{KEYWORDS: Hair Concrete, Bio Concrete, Compressive Strength, Splitting Tensile Strength. and Flexural Strength.}

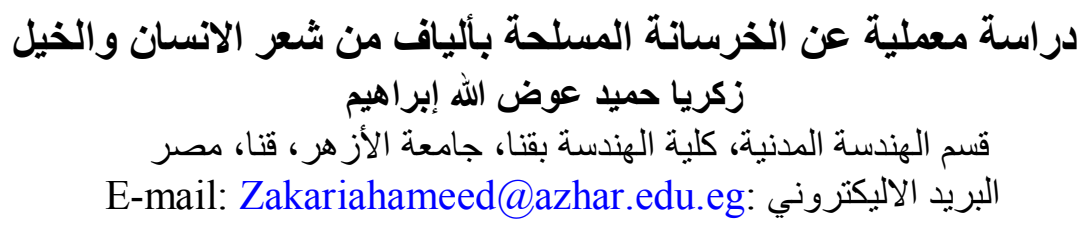

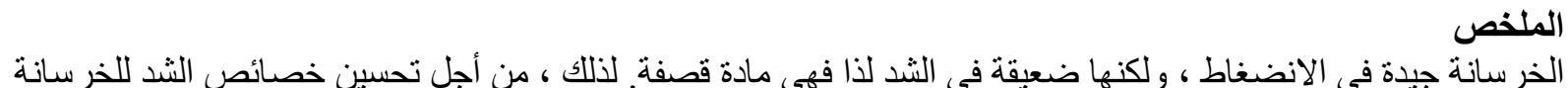

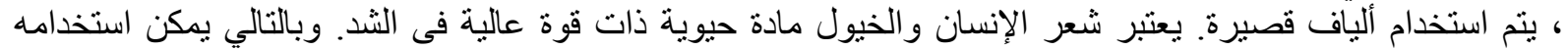

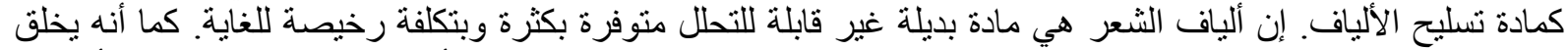

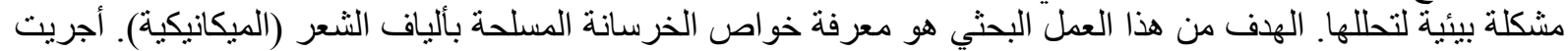

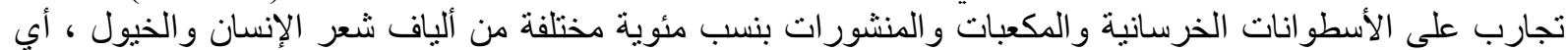

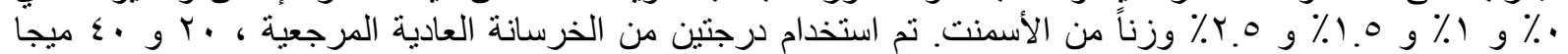

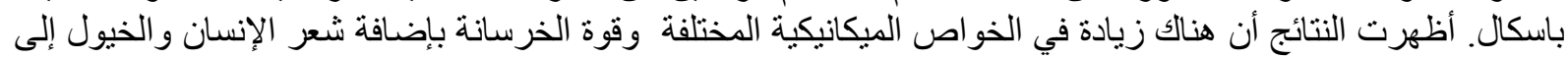
الخرسانة. الكلمات المفتاحية : خرسانة الثعر، الخرسانة الحيوية، مقاومة الضغط ، مقاومة الانفلاق للشد، و مقاومة الإنحناء.

\section{INTRODUCTION}

Biological fibers have been already used some 3400 years ago in composite material in the ancient Egyptians, where straw and clay were mixed together to make mud bricks. Now a day 
there was a trend to use a bio material in concrete to enhance the tensile properties of concrete elements. Some of these materials are human and horse hair fibers $[7,8]$.

Human hair is a material considered useless in most societies and therefore is found in municipal waste stream in almost all cities and towns of the world [1],[10]. In 2010, India alone exported approximately 1 million $\mathrm{kg}$ of human hair and its products worth US \$238 million, and total global imports were valued at US \$ 1.24 billion [2].

Hair is used as a fiber reinforcing material in concrete for its high tensile strength, can minimize an environmental problem, to control plastic shrinkage and dry shrinkage cracking, to lower the permeability of concrete, very low cost and to prevents it from spalling [1],[9]. But with these advantages of using hair fiber in concrete, many disadvantages are also there in which major drawback of using fiber is its fabrication. The process of spreading fibers into the cement matrix is labour intensive and costlier than the production of simple concrete or plain concrete. The major advantages gained by the use of FRC overcome this disadvantage. The fiber is often described by a convenient parameter called aspect ratio. The aspect ratio of the fiber is defined as the ratio of its length to its diameter [3][6].

As per a report of 1981 which has been published in Britain, it has been stated that human hairs can be used in the form of fiber reinforcement in roofing where precast concrete is used specially in houses with lower cost (Ahmad et al, 2011)[1], The main function of using fiber in a concrete is to prevent the growth of cracks. Also by using a fiber reinforced concrete it also improves resistance to dynamic loading, shear strength, resistance to wear, resistance to shock, impact resistance, also provides ductility against seismic activities and blast. Apart from enhancing properties of concrete fiber reinforced concrete is also economical and more durable as compared to the normal conventional concrete [2],[4].

Sinan A. (2013)[9] studied the experimental investigation into the mechanical properties of new natural fiber reinforced mortar by using a human hair fiber (HHF) as a reinforced material. Tests were carried to study the influence of fiber content on the compressive strength, splitting tensile strength, flexural strength and load deflection was presented for two $\mathrm{w} / \mathrm{c}$ ratios (0.6 and 0.7). An improvement in the energy absorption capacity due to the fiber addition was observed, and the optimum fiber volume fracture was seen to be $0.8 \%$. Energy absorption capacity and ductility factor were improved considerably with fiber content increased, which makes using the HHF suitable for seismic force resistant structures.

\section{EXPERIMENTAL WORK}

The experimental program was carried out to test one hundred and forty four concrete specimens of cubes, cylinders and prisms containing different percentages of human or horse hairs fibers. Two grades of concrete were used, 20 and $40 \mathrm{MPa}$.

\subsection{Materials}

\section{a. Fine Aggregate (Sand)}

Clean and round fine aggregate was used. The sand was washed and dried in open area before used. The sand grading was maintained by using sieves according to ECP (Egyptian Code of Practice No 203, 2001)[5]. Very fine material was excluded from the mixture by using fine sieves. The properties of fine aggregates are given in Table1.

\section{b. Coarse Aggregate (Gravel)}

Round, well-graded and clean gravel was used in the mixture with two sizes of (10 and 20) $\mathrm{mm}$. The gravel was washed using potable water to ensure the removal of dust or impurities that might exist. The properties of coarse aggregates are given in Table1.

\section{c. Cement}

Ordinary Portland cement (Assiut Cement) was used throughout the program for making concrete. The fineness degree, Initial and final setting times and the mortar compressive strength were measured according to Egyptian Code of Practice (ECP 2032007)[5]. The properties of cement are mentioned in Table 2.

\section{d. Water}

Potable water was used in the mixes. Chemical analysis of such water showed that it was suitable for the used cement to allow for full hydration. 


\section{e. Additive}

Two types of additives were used in concrete with grade $40 \mathrm{MPa}$, Silica fume and addicrete BVF.

\section{f. Hair}

Two types of hair were used in the experimental program, human and horse hairs. The human hairs were collected from salons and the horse hairs were collected from farm for breeding horses. The hair was separate from other wastes and washed to remove impurities. The hair were properly dried either under sun light. After the hair dried it is cut into small parts. The mechanical properties of used hair fiber are shown in Table3.

Table 1: Properties of Aggregate.

\begin{tabular}{|c|c|c|}
\hline Property & $\begin{array}{c}\text { Fine aggregate } \\
\text { (Sand) }\end{array}$ & $\begin{array}{c}\text { Coarse aggregate } \\
\text { (Gravel) }\end{array}$ \\
\hline Water absorption (\%) & 1.19 & 0.74 \\
\hline Fineness modulus & 2.83 & 6.98 \\
\hline Bulk density ( kg/m3) & 1.59 & 1.78 \\
\hline Specific gravity & 2.62 & 2.76 \\
\hline
\end{tabular}

Table 2. Properties of Cement.

\begin{tabular}{|c|c|c|}
\hline \multicolumn{2}{|c|}{$\%$ of Retained on Sieve No. 170} & 4.7 \\
\hline \multicolumn{2}{|c|}{ Initial setting times (min) } & 96 \\
\hline \multicolumn{2}{|c|}{ Final setting times (min) } & 254 \\
\hline \multirow{2}{*}{$\begin{array}{c}\text { Mortar compressive strength } \\
(\mathrm{MPa})\end{array}$} & 3 days & 19.55 \\
\hline & 7 days & 29.14 \\
\hline
\end{tabular}

Table 3. Properties of Hair Fiber.

\begin{tabular}{|c|c|c|}
\hline Hair type & Human hair & Horse hair \\
\hline Hair diameter $(\mu \mathrm{m})$ & $90-130$ & $110-150 \mu \mathrm{m}$ \\
\hline Hair length $(\mathrm{mm})$ & $20-60$ & $50-100$ \\
\hline Tensile strength $(\mathrm{MPa})$ & 325 & 405 \\
\hline
\end{tabular}

Table 4: Properties of the Concrete Mixture.

\begin{tabular}{|c|c|c|c|c|c|c|c|}
\hline $\begin{array}{c}\text { Target } \\
\text { concrete } \\
\text { trength } \\
(\mathrm{kg} / \mathrm{cm} 2)\end{array}$ & $\begin{array}{c}\text { Cement } \\
\mathrm{kg} / \mathrm{m} 3\end{array}$ & $\begin{array}{c}\text { Sand } \\
\mathrm{kg} / \mathrm{m} 3\end{array}$ & $\begin{array}{c}\text { Aggregate } \\
(\mathrm{A}) \\
\mathrm{kg} / \mathrm{m} 3\end{array}$ & $\begin{array}{c}\text { Aggregate } \\
(\mathrm{B}) \\
\mathrm{kg} / \mathrm{m} 3\end{array}$ & $\begin{array}{c}\text { Silica } \\
\text { Fume } \\
\mathrm{kg} / \mathrm{m} 3\end{array}$ & $\begin{array}{c}\text { Addicrete } \\
\text { (BVF) } \\
\text { Liter/m3 }\end{array}$ & $\begin{array}{c}\text { Water } \\
\text { Litter/m3 }\end{array}$ \\
\hline 200 & 250 & 630 & 655 & 655 & -- & -- & 182 \\
\hline 400 & 450 & 570 & 610 & 610 & 15 & 5 & 170 \\
\hline
\end{tabular}

\subsection{Specimen Preparation}

The concrete mix design is done in accordance to Egyptian Code of Practice (ECP 2032007)[5]. Two concrete compressive strength were designed. The propertied of concrete mix are shown in Table 4. In the present experimental investigation, the total number of specimens casted was 144. The cubes, cylinders and prisms casted were (48, 48 and 48) respectively. The main parameters of the experimental program were type of hair fiber used, the percentages of hair fiber by weight of cement and the grade of concrete compressive strength. All the specimens were tested for 28-day strength. Table 5 summarized the experimental program of the tested specimens. 
Table 5: Summarized the Experimental Program of the Tested Specimens.

\begin{tabular}{|c|c|c|c|c|c|}
\hline $\begin{array}{c}\text { Concrete } \\
\text { grade }\end{array}$ & $\begin{array}{l}\text { Hair } \\
\text { type }\end{array}$ & \% Hair & $\begin{array}{l}\text { No. of } \\
\text { Cube }\end{array}$ & $\begin{array}{c}\text { No. of } \\
\text { Cylinder }\end{array}$ & $\begin{array}{l}\text { No. of } \\
\text { Prism }\end{array}$ \\
\hline \multirow{4}{*}{ M20 } & \multirow{8}{*}{ human } & 0 & 3 & 3 & 3 \\
\hline & & 1 & 3 & 3 & 3 \\
\hline & & 1.5 & 3 & 3 & 3 \\
\hline & & 2.5 & 3 & 3 & 3 \\
\hline \multirow{4}{*}{ M40 } & & 0 & 3 & 3 & 3 \\
\hline & & 1 & 3 & 3 & 3 \\
\hline & & 1.5 & 3 & 3 & 3 \\
\hline & & 2.5 & 3 & 3 & 3 \\
\hline \multirow{4}{*}{ M20 } & \multirow{8}{*}{ horse } & 0 & 3 & 3 & 3 \\
\hline & & 1 & 3 & 3 & 3 \\
\hline & & 1.5 & 3 & 3 & 3 \\
\hline & & 2.5 & 3 & 3 & 3 \\
\hline \multirow{4}{*}{ M40 } & & 0 & 3 & 3 & 3 \\
\hline & & 1 & 3 & 3 & 3 \\
\hline & & 1.5 & 3 & 3 & 3 \\
\hline & & 2.5 & 3 & 3 & 3 \\
\hline
\end{tabular}

\section{TEST PERFORMED}

144 cubes, cylinders and beams are tested and analyzed for finding the effect of using hair as fiber reinforcement on the mechanical properties of hair concrete. For determining the effect of hair as fiber in concrete following test were performed.

\subsection{Compressive strength test}

The compressive strength of concrete is one of most important properties of concrete in most structural applications. The test was conducted as Egyptian Code of Practice (ECP 2032007)[5]. Cube specimens of dimensions $150 \times 150 \times 150 \mathrm{~mm}$ were cast for M20 and M40 grades of concrete. See Fig (1). After curing, these cubes were tested on compression testing machine as shown in Figs (2), (3). The failure load was noted in each category three cubes were tested and their average value is reported. The compressive strength was calculated as follows, Compressive strength $(\mathrm{MPa})=$ Failure load / cross sectional area.

\subsection{Splitting tensile test}

The tensile test for 48 concrete cylinder specimens with $150 \mathrm{~mm} \times 300 \mathrm{~mm}$ was carried out as shown in Figs (2), (3). The samples were tested under testing machine after curing period of 28 days. The maximum load was noted and the splitting tensile strength was calculated as:

Splitting tensile Strength $\mathrm{ft}=2 \mathrm{P} / \pi \mathrm{DL}$

Where, $\mathrm{P}=$ Ultimate Load $(\mathrm{N}), \mathrm{D}=$ diameter of cylinder $(\mathrm{mm})$ and $\mathrm{L}=$ length of cylinder $(\mathrm{mm})$.

\subsection{Flexural Strength Test}

Flexural test is the measure of strength of concrete in bending. Normal concrete beams and hair reinforced concrete beams of size $100 \mathrm{~mm} \times 100 \mathrm{~mm} \times 500 \mathrm{~mm}$ are tested using a flexure testing machine see Figs (2), (4). The specimen is simply supported on the two rollers of the machine which are $400 \mathrm{~mm}$ apart, with a bearing of $50 \mathrm{~mm}$ from each support. The load shall be applied on the beam from two rollers which are placed above the beam with a spacing of $200 \mathrm{~mm}$. The load is applied at a uniform rate till the specimen fails. The maximum value of the load applied is reported and the flexural strength was calculated as:

Flexural Strength $\boldsymbol{f}_{b t}=\mathbf{P L} / \mathbf{b d}^{2}$

Where, $\mathrm{P}=$ Ultimate Load $(\mathrm{N}), \mathrm{L}=$ span between two supports $(\mathrm{mm}), \mathrm{b}=$ width of beam and $\mathrm{d}=$ depth of $(\mathrm{mm})$ 


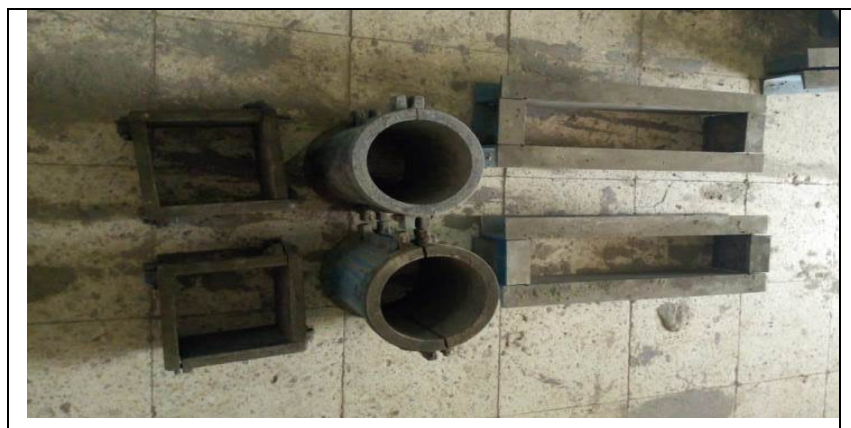

Fig.1. Cubes, cylinders and Prisms Molds.

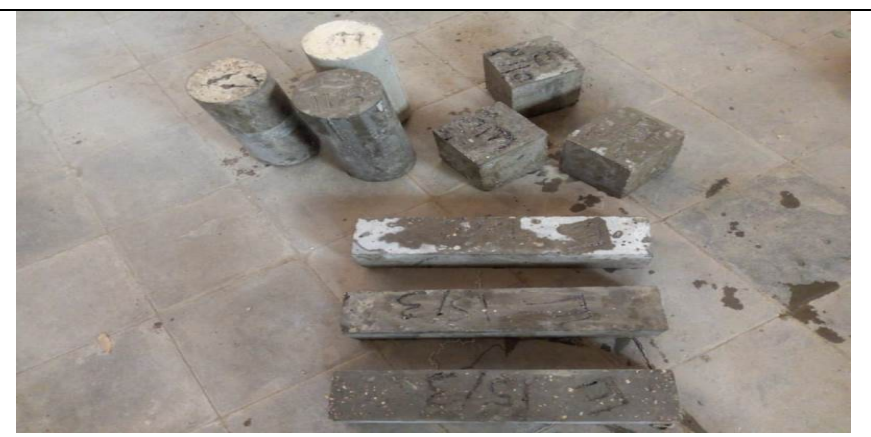

Fig.2. Concrete Specimens of Cubes, Cylinders and Prisms after Casting and Curing.

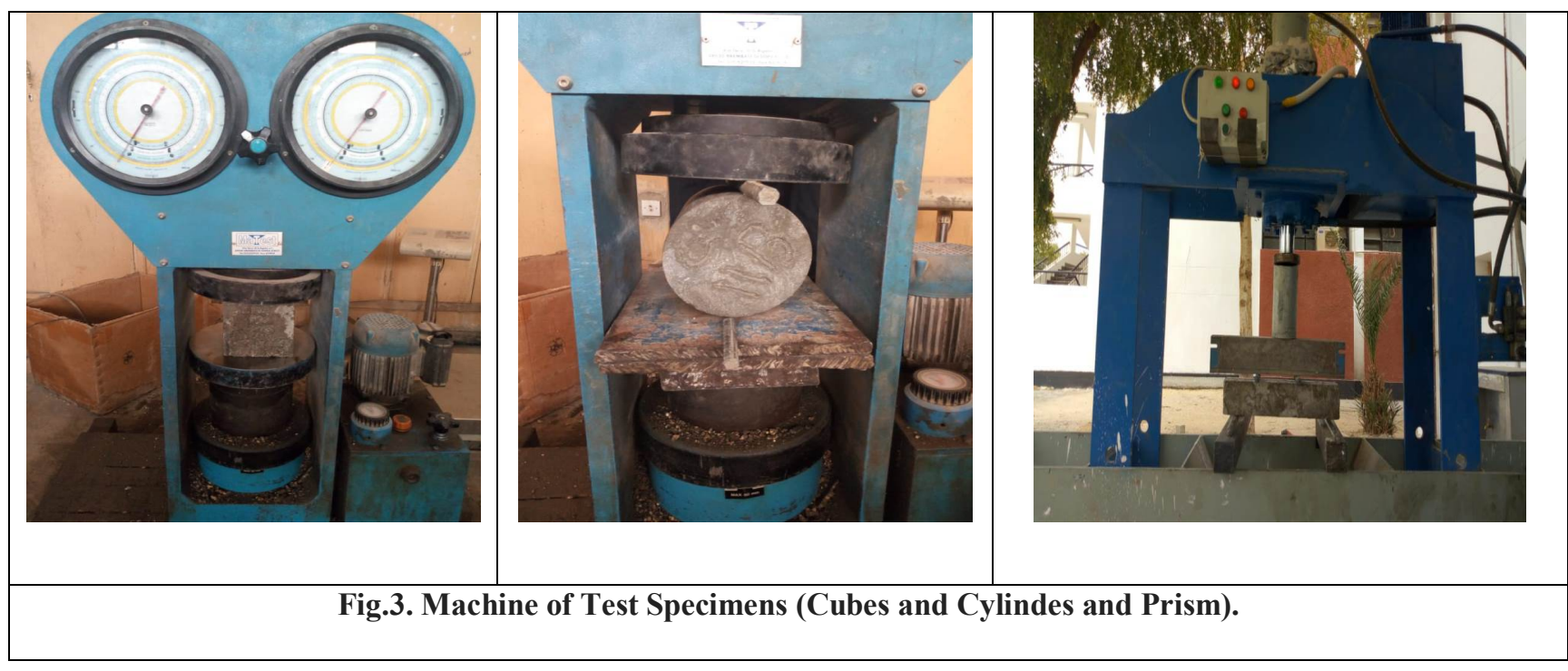

\section{RESULTS AND DISCUSSIONS}

The mechanical properties of concrete are tested on M20 and M40 grades concrete specimens, with and without hair reinforcement. Human and horse hair were used. The percentage of hair fiber is varying from $0 \%$ to $2.5 \%$ by weight of cement. During the casting of test samples, it was observed that mixing of hair in the concrete to achieve homogeneity is a problem at concentration above $1 \%$ of human and horse hair, resulting in balling and lumping of hair fibers. The results are briefly tabulated, figured and the comparison between hair fiber reinforced concrete and plain cement concrete were shown below.

\subsection{Compression Strength Test}

The compressive strength results which were obtained after testing the samples are given in the Table (6) and Figures $(4,5)$. The samples were tested after 28 days only. It was obvious from the Table and Figure that:

1. When M20 concrete grade was used with $1 \%$ human hair and compared with the plain cement concrete, it was found that there was an increase of $5.79 \%$ in compressive strength and with $1.5 \%$ there was an increase of $13.04 \%$ in compressive strength. When the human hair content reached to $2.5 \%$ a reduction in the strength of concrete by $1.74 \%$ were noticed. This means that the optimum human fiber content was taken as $2 \%$ of cement content. 
2. When M40 concrete grade was used with $1 \%$ human hair and compared with the plain cement concrete, it was found that there was an increase of $3.09 \%$ in compressive strength, with $1.5 \%$ hair there was an increase of $9.04 \%$ in compressive strength and with $2.5 \%$ human hair content, there was an decreased of $3.62 \%$ in compressive.

3. When M20 concrete grade was used with 1\% horse hair and compared with the plain cement concrete, it was cleared that there was an increase of $6.76 \%$ in compressive strength and with $1.5 \%$ there was an increase of $14.49 \%$ in compressive strength and with $2.5 \%$ horse hair there was an increase of $24.15 \%$ in compressive strength.

4. When M40 concrete grade was used with $1 \%$ horse hair and compared with the plain cement concrete, it was found that there was an enhancement in compressive strength with about $5.23 \%$, with $1.5 \%$ hair there was an increase of $9.52 \%$ in compressive strength and with $2.5 \%$ horse hair there was an increase of $11.67 \%$ in compressive strength.

\section{Also it is noticed that the horse hair fiber addition to concrete is better than human hair fiber to raise the concrete compressive strength.}

Table 6: Average Compressive strength of Hair Concrete

\begin{tabular}{|c|c|c|c|}
\hline \multirow{4}{*}{$\begin{array}{c}\text { Concrete } \\
\text { grade }\end{array}$} & \% Hair & \multicolumn{2}{|c|}{$\begin{array}{c}\text { Average Concrete } \\
\text { Compressive strength } \\
\text { (MPa) }\end{array}$} \\
\cline { 3 - 4 } & & $\begin{array}{c}\text { Human } \\
\text { hair }\end{array}$ & $\begin{array}{c}\text { Horse } \\
\text { hair }\end{array}$ \\
\hline \multirow{4}{*}{ M20 } & 0 & 20.7 & 20.7 \\
\cline { 2 - 4 } & 1 & 21.9 & 22.1 \\
\cline { 2 - 4 } & 1.5 & 23.4 & 23.7 \\
\hline \multirow{4}{*}{ M40 } & 2.5 & 23 & 25.7 \\
\cline { 2 - 4 } & 0 & 42 & 42 \\
\cline { 2 - 4 } & 1 & 43.3 & 44.2 \\
\cline { 2 - 4 } & 1.5 & 45.8 & 46 \\
\hline
\end{tabular}

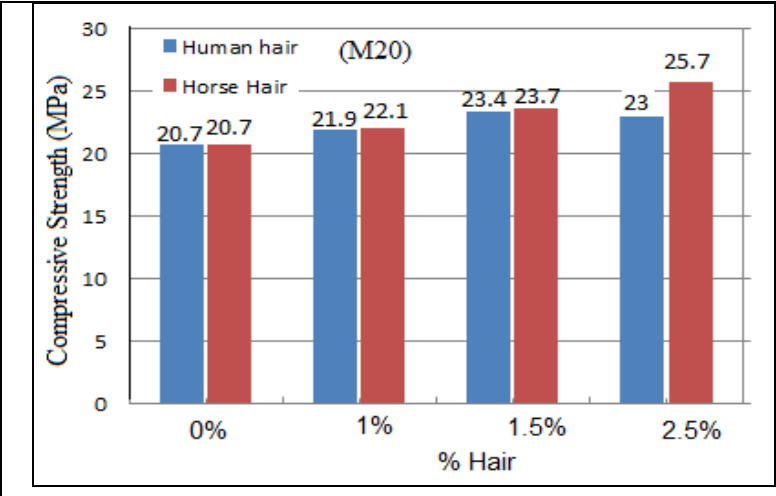

Fig.4. Variation of compressive strength with $\%$ hair for concrete grade 20 MPa.

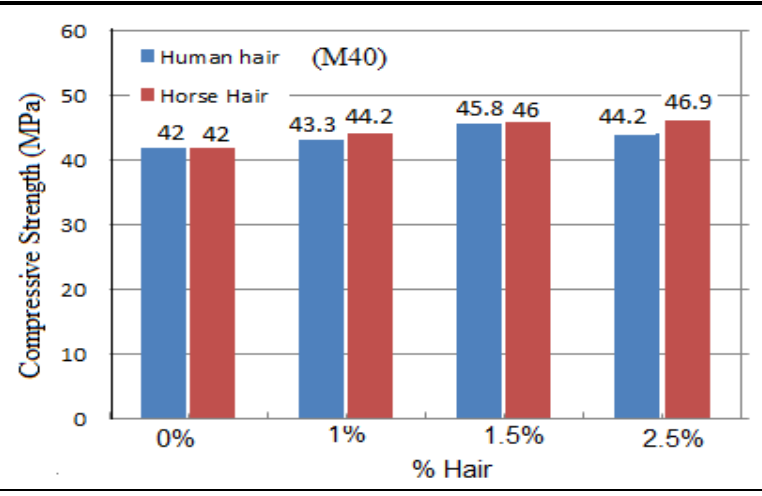

Fig.5. Variation of compressive strength with \% hair for concrete grade 40 MPa.

\subsection{Split Tensile Strength Test}

The splitting tensile test was conducted on the standard samples of the cylinder concrete which is reinforced with hair fiber after 28 days. The results obtained were shown in the Table (7) and Figs $(6,7)$. It is clear from the table and figures that:- 
1. When M20 concrete grade was used with $1 \%$ human hair and compared with the plain cement concrete, it was found that there is an increase of $1.92 \%$ in tensile strength and with $1.5 \%$ there was an increase of $6.57 \%$ in tensile strength and with $2.5 \%$ human hair there was a drop in tensile strength by $2.91 \%$.

2. When M40 concrete grade was used with $1 \%$ human hair and compared with the plain cement concrete, it was found that there was an increase of $1.82 \%$ in tensile strength, with $1.5 \%$ hair there was an increase of $2.73 \%$ in tensile strength and with $2.5 \%$ human hair there was an decreased of $7.71 \%$ in tensile strength.

3. When M20 concrete grade was used with $1 \%$ horse hair and compared with the plain cement concrete, it was found that there was an enhancement in tensile strength of about $3.90 \%$ and with $1.5 \%$ there was an increase of $5.85 \%$ in tensile strength and with $2.5 \%$ horse hair there was an increase of $6.58 \%$ in tensile strength.

4. When M40 concrete grade was used with $1 \%$ horse hair and compared with the plain cement concrete, it was found that there was an increase of $2.68 \%$ in tensile strength, with $1.5 \%$ hair there was an increase of $2.76 \%$ in compressive strength and with $2.5 \%$ horse hair there was an increase of 5.51\% in tensile strength.

Also it was noticed that the horse hair fiber addition to concrete is better than human hair fiber to raise the concrete splitting tensile strength.

Table 7: Average Splitting Tensile Strength of Hair Concrete

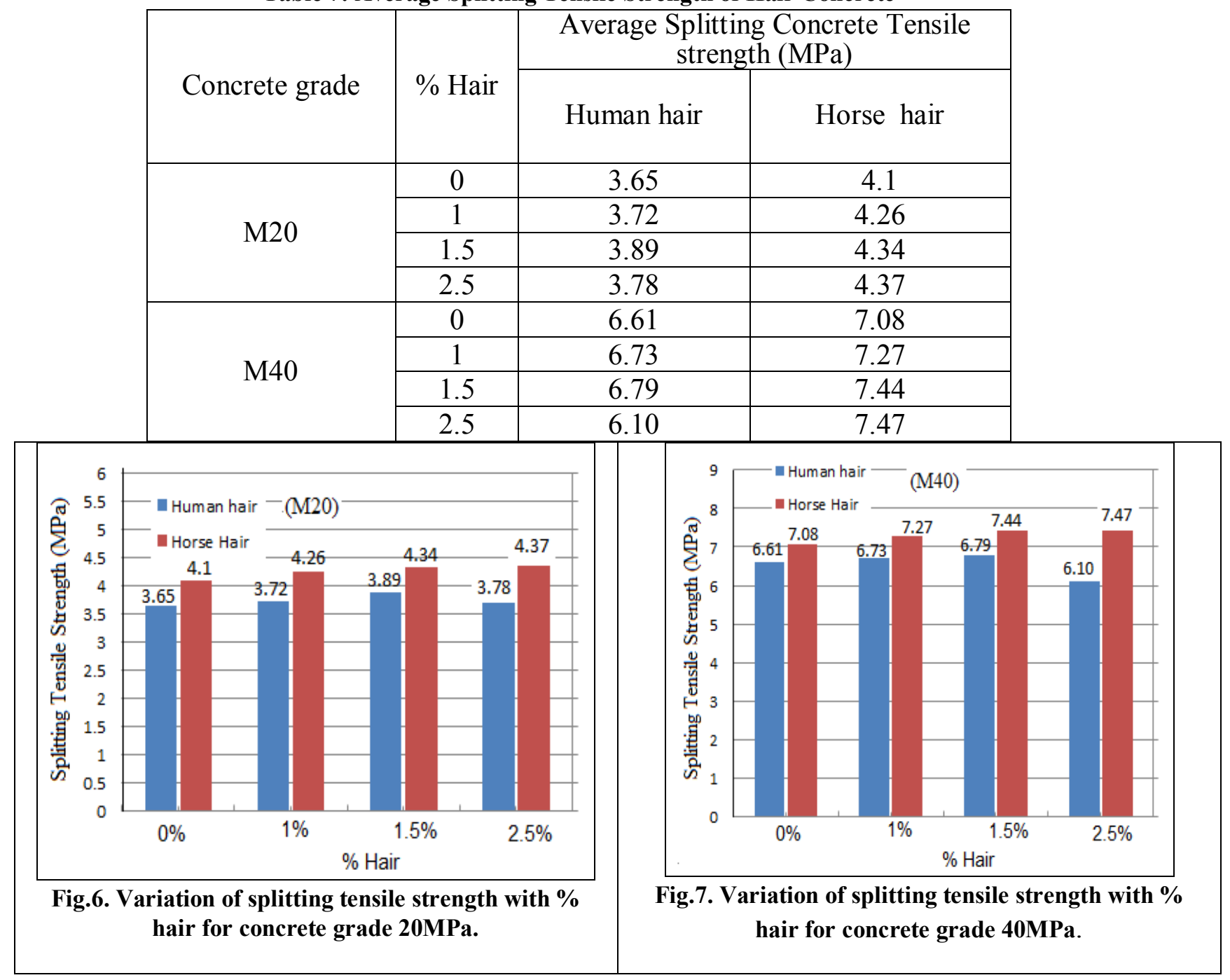




\subsection{Flexural Tensile Test}

This test was carried out on beam samples whose dimensions are $10 \mathrm{~cm}$ width, $10 \mathrm{~cm}$ depth and $50 \mathrm{~cm}$ length and casted with different amount of hair fiber added as percentage by weight of cement. The values of flexural strength obtained were shown in the Table (8) and Figs $(8,9)$. From the Table and Figures, it was clear that:

1. There was an increase in flexural strength of concrete prism when M20 concrete grade was used with 1 and $1.5 \%$ human hair. This increase was 1.34 and $5.13 \%$ respectively. Also, compared with the plain cement concrete, it is found that there is a decreased of $1.59 \%$ in tensile strength when used $2.5 \%$ human hair.

2. When M40 concrete grade was used with $1 \%$ human hair and compared with the plain cement concrete, it is found that there is an increase of $0.91 \%$ in tensile strength, with $1.5 \%$ hair there is an increase of $5.19 \%$ in tensile strength and with $2.5 \%$ human hair there is a drop of $6.85 \%$ in flexural strength.

3. When M20 concrete grade was used with $1 \%$ horse hair and compared with the plain cement concrete, it is found that there is an enhancement in tensile strength of about $1.48 \%$ and with $1.5 \%$ there is an increase of $3.81 \%$ in tensile strength and with $2.5 \%$ horse hair there is an increase of $9.74 \%$ in flexural strength.

4. When M40 concrete grade was used with $1 \%$ horse hair and compared with the plain cement concrete, it is found that there is an increase of $1.89 \%$ in flexural strength, with $1.5 \%$ hair there is an increase of $4.65 \%$ in flexural strength and with $2.5 \%$ horse hair, there is an increase of $7.42 \%$ in flexural strength.

5. The experimental results showed that upon failure load the control concrete prism was separated into parts and the brittle failure was occurred. When the hair fiber was added the mode of failure were changing from brittle type of failure to a more ductile failure.

Table 8: Average Flexural Strength of Hair Concrete

\begin{tabular}{|c|c|c|c|}
\hline \multirow{3}{*}{ Concrete grade } & \multirow{2}{*}{ \% Hair } & \multicolumn{2}{|c|}{ Average Flexural Strength (MPa) } \\
\cline { 3 - 4 } & & Human hair & Horse hair \\
\hline \multirow{4}{*}{ M20 } & 0 & 4.48 & 4.72 \\
\cline { 2 - 4 } & 1 & 4.54 & 4.79 \\
\cline { 2 - 4 } & 1.5 & 4.71 & 4.90 \\
\cline { 2 - 4 } & 2.5 & 4.92 & 5.18 \\
\hline \multirow{4}{*}{ M40 } & 0 & 6.55 & 6.87 \\
\cline { 2 - 4 } & 1 & 6.61 & 7.0 \\
\cline { 2 - 4 } & 1.5 & 6.89 & 7.38 \\
\cline { 2 - 4 } & 2.5 & 7.22 & \multicolumn{2}{|c}{} \\
\hline
\end{tabular}




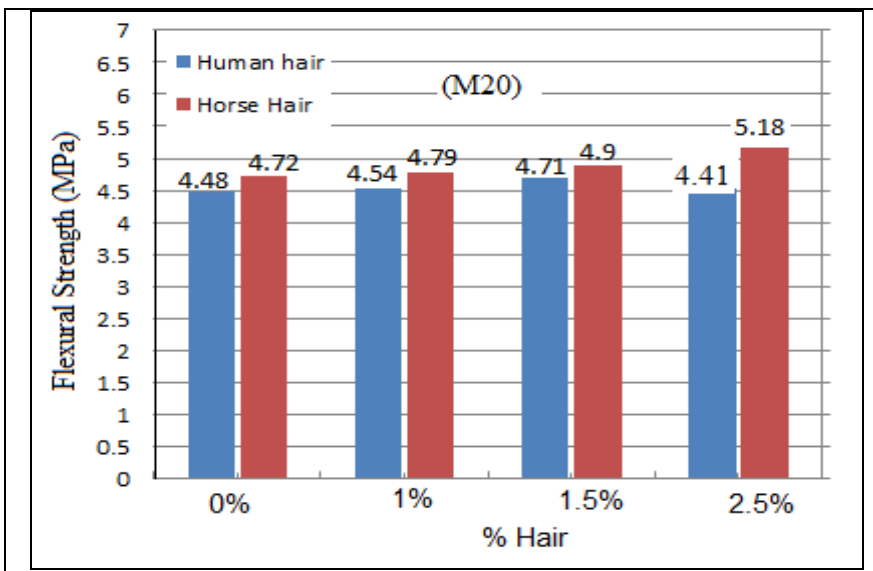

Fig.8. Variation of flexural strength with \% hair for concrete grade $20 \mathrm{MPa}$.

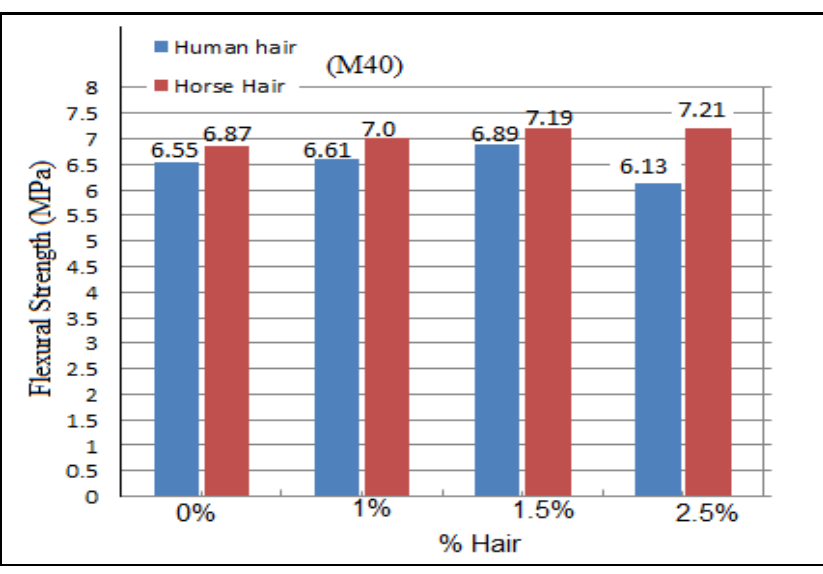

Fig.9. Variation of flexural strength with \% hair for concrete grade $40 \mathrm{MPa}$.

\section{CONCLUSION}

According to the experimental tests performed it is observed that:-

1. There was remarkable increment in properties of concrete according to the percentages of hairs by weight in concrete.

2. When M20 and M40 concrete grade with 1 and 1.5\% human hair was compared with the plain cement concrete, it is found that there was an increase of $(5.79,13.04) \%$ and $(3.09,9.04) \%$ in compressive strength, $(1.92,6.57) \%$ and $(1.82,2.73) \%$ in splitting tensile strength and $(1.34,5.13)$ and $(0.91,5.19) \%$ in flexural strength respectively.

3. When M20 and M40 concrete grade with 2.5\% human hair was compared with the plain concrete, it was found that there was a decreased of $(1.74,3.62) \%$ in compressive strength, $(2.91,7.71) \%$ in splitting tensile strength and $(1.59,6.85)$ in flexural strength respectively.

4. When M20 concrete grade with 1, 1.5 and 2.5\% horse hair was compared with the plain cement concrete, it was found that there was an increase of $6.76,14.49$ and $24.15 \%$ in compressive strength, $3.90,5.85$ and 6.58 in splitting tensile strength and $1.48,3.81$ and $9.74 \%$ in flexural strength.

5. When M40 concrete grade with $1,1.5$ and $2.5 \%$ horse hair was compared with the plain cement concrete, it was found that there was an increase of 5.23, 9.52 and $11,67 \%$ in compressive strength, 2.68, 2.76 and 5.51 in splitting tensile strength and $1.89,4.65$ and $7.42 \%$ in flexural strength.

6. The experimental results showed that upon failure load the control concrete prism was separated into parts and the brittle failure was occurred. When the human and horse hair fiber was added the mode of failure were changing from brittle type of failure to a more ductile failure.

7. The optimum human fiber content was taken as $2 \%$ of cement content.

8. The addition of horse hair fiber gives the better mechanical properties of concrete strength than horse hair fibers. 


\section{REFERENCE}

1. Ahmed S., Ghani F. and Hasan M, (2011) "Use of Waste Human Hair as Fiber Reinforcement in Concrete", IEI Journal, Volume 91 FEB, Page no 43.

2. Akarsh Verma1, V. K. Singh1, S. K. Verma and Anshul Sharma, (2016)," Human Hair: A Biodegradable Composite Fiber", International Journal of Waste Resources, Vol. 6, Issue 2.

3. Akash Sharma et al. (2017), Analysis of Fibre Reinforced Concrete: Using Human Hair as A Fibre Reinforcement. International Journal Recent Science Resources. 8(4), pp. 16715-16720.

4. Ashish Kumar Dwivedi, Dr. Arvind Saran Darbari, Vinod Kumar Verma, (2015), "Compressive strength evaluation of Human hair and Polypropylene fabricated reinforced composite", The International Journal of Engineering and Science (IJES), Vol. 4, pp-2319-1805.

5. ECP-203, (2001): Egyptian code for design and construction of reinforced concrete structures, ECPCS-203. Housing and Building National Research Center. Ministry of Housing, Utilities and Urban Planning, Cairo.

6. Hamidullah Naik, Nissar Ahmad Naikoo, (2015) "Use of horse hair as fibrous material in concrete By IS Code 10262 : 2009", International Journal of Advanced Research, Volume 3, Issue 6, 1569-1572.

7. Jain D. And Kothari A "Hair Fibre Reinforced Concrete, (2012)" Research Journal of Recent Sciences Vol. 1(ISC-2011), 128-133.

8. Khansaheb A. P, (2015) "Experimental Investigation on Properties of Concrete Using Human Hair \& Sugarcane Bagasse Ash", International Journal of Innovative and Emerging Research in Engineering Volume 2, Issue 5.

9. Sinan Abdulkhaleq Yaseen, (2013) "An Experimental Investigation into the Mechanical Properties of New Natural Fibre Reinforced Mortar", Eng. \& Tech. journal, Vol. 31, Part(A), No.10.

10. Tomas U. Ganiron, (2014), "Effects of Human Hair Additives in Compressive Strength of Asphalt Cement Mixture" By AS Code 3600 : 2001", International Journal of Advance Science and Technology Vol.67.

11. T. Naveen Kumar1, (2015), “An Experimental Study on Mechanical Properties of Human Hair Fibre Reinforced Concrete" IOSR Journal of Mechanical and Civil Engineering, Vol. 12, pp 65-75. Vol.15, No. 56, July, 2020, 444-458bn 